\title{
Modeling of dynamic conditions of operation of wind turbines (WT) and choice of environmentally efficient and energy economic technology of wind power energy transformation
}

\author{
Vadim Bespalov ${ }^{1, *}$, Oksana Gurova ${ }^{1}$, Oksana Akay $^{1}$ and Mikhail Izotov ${ }^{1}$ \\ ${ }^{1}$ Don State Technical University, 344000 Rostov-on-Don, Russia
}

\begin{abstract}
Wind energy usage is one of the promising areas among renewable energy sources. The article considers a methodical approach to the modeling and selection of environmentally efficient and energyefficient wind turbines at the design stage, taking into account the characteristics of the natural-territorial complex and the specific anthropogenic load on the territory of the WT location.
\end{abstract}

\section{Introduction}

The practical use of renewable energy sources (RES) is growing in many countries of the world [1]. The leading place among them is occupied by wind power plants (WPP) capable of generating sufficiently large amount of electricity for consumers of different scale varying from single or group installations up to networked ones (wind power plant).

The main advantages of wind turbines are the inexhaustibility of wind energy, the relative environmental safety of the energy received and the possibility of placement at any location. The shortcomings that limit the wide use of windmills include a narrow range of wind speed characteristics use from 2 to $15 \mathrm{~m} / \mathrm{s}$, variable work depending on the wind direction change, and a long payback term of the installation.

Further progress in the development of wind turbines, in our view, should be based on optimizing the management of wind turbines through modeling a dynamic and rather complex technology for converting wind energy into electrical energy $[2,3]$.

In the current conditions for the wind turbines development, it becomes necessary to develop criteria for assessing and selecting the type of installation and optimizing the technological parameters of power generation $[4,5]$. The study of the most frequently used methods of assessment and selection of optimal wind turbines parameters taking into account the necessary volumes of electricity received and the facility location made it possible to identify their shortcomings:

- a need to pre-assign a specific type of equipment;

- lack of sufficient energy characteristics of equipment based on the complex impact on the environment state and the comfort of living of the population in the area of WT location.
At present, in connection with the existing variety of wind turbines, it becomes necessary to manage the process of selecting the type of installation, based on the principles of energy efficiency and environmental efficiency. By the term «energy efficiency» we mean the share of energy (useful energy) used by the WT regarding to the entire wind potential of the territory. By the term «environmental efficiency» we mean the degree of reduction of negative factors (noise, vibration, etc.) that are provided by the WT to the environment during its operation in a particular area [6].

The proposed technique allows to simulate the conversion technology of wind energy into electric energy in various natural and climatic conditions, to evaluate various options for implementing this technology and to select the optimal option with a subsequent calculation of the WT technological parameters.

\section{Materials and Methods}

The main goal of our research is to provide the ability to manage a very complex dynamic technology for converting wind energy into electricity based on the technology simulation, calculating and selecting the optimal technological parameters of WT based on the energy efficiency and environmental efficiency criteria. This methodological approach allows to choose the most environmentally efficient and energy-efficient technology. To achieve this goal, we have accomplished the following tasks:

- system analysis of natural and climatic factors and landscape characteristics of the planned territory for the WT location has been done;

- the parameters describing the main characteristics of the WT have been singled out and formalized;

\footnotetext{
* Corresponding author: izos-rgsu@mail.ru
} 
- a mathematical description of the environmental and energy efficiency as resulting evaluation criteria for the technology of WT conversion to electricity has been performed;

- the technology, based on the calculated resulting criteria has been chosen;

- a methodology for assessing and selecting the most environmentally and energy-efficient technology for converting wind energy into electrical energy with subsequent calculation of design parameters of wind turbines for certain territorial conditions has been developed.

\section{Results}

The performed analysis of the technical and economic characteristics of the WT currently in operation on the territory of the Russian Federation showed their compliance with modern indicators of foreign power plants.

However, it should be noted that any modern WT are subjected to constant technical improvement, and therefore, when choosing a particular type of such plants, their quality should be considered at the time of the intended use. The cost of such wind turbines does not exceed the cost of foreign analogs [7,8].

As a result of research of WT different types, we can state that, despite their wide application, they still have two main drawbacks: the wind utilization factor does not exceed 0.4 ; their use in the immediate vicinity of the consumer is hampered by the increased environmental hazard of these installations (in particular, the level of sound volume that exceeds the standard values).

Further improvement of WT (the capacity unit increase, the wind energy use coefficient increase to 0.5 and more, and improvement of their ecological characteristics) is possible on the basis of the use of slowmoving orthogonal WT with a vertical axis [9-14].

Thus, at present there is a sufficient number of WT on the energy market that can be used in both autonomous and centralized power supply systems.

We examined the main parameters that determine, in the final analysis, the design perfection, ecological efficiency and energy efficiency of operation of the WT.

Thus, the kinetic energy of the air (wind) flow per time unit can be determined by the formula:

$$
K=m / V^{2}, \mathrm{BT},
$$

where $m$ is the mass air flow rate, $\mathrm{kg} / \mathrm{s} ; V$ - wind speed, $\mathrm{m} / \mathrm{s}$.

In this case, the mass flow rate of air flow through the plane of the wind wheel is determined by the formula:

$$
m=\rho \cdot V \cdot S, \mathrm{~kg} / \mathrm{s},
$$

where $\rho$-air density, $\mathrm{kg} / \mathrm{m}^{3} ; S$ - area brushed by the wind wheel, $\mathrm{m}^{2}$.

The area brushed by the wind wheel can be determined for the axial wind turbines with the formula:

$$
S=\pi \cdot D^{2} / 4, \mathrm{~m}^{2},
$$

and for orthogonal wind turbines according to the formula:

$$
S=D H, \mathrm{~m}^{2},
$$

where $D$ is the diameter of the axial or orthogonal wind wheel, $\mathrm{m}^{2} ; H$-height of the orthogonal wind wheel, $\mathrm{m}$.

Wind power:

$$
P=\rho V^{3} S / 2, \mathrm{~W} .
$$

Thus, the energy supplying the wind wheel is proportional to the cube of the incoming air flow speed (wind speed).

The main characteristics of the wind wheel are:

- power factor, determined by the formula:

$$
C_{p}=P_{w w} / P,
$$

- coefficient of the peripheral forces moment defined by the formula:

$$
C_{m}=2 M / q \cdot F \cdot D
$$

where $P_{w w}$ - the stream power used by a wind wheel during its rotary motion, $\mathrm{W} ; \mathrm{M}$ is the moment created by the peripheral force, $\mathrm{N} \cdot \mathrm{m} ; q$ - speed head, defined by the formula:

$$
q=\rho \cdot V^{2} / 2, \mathrm{H} / \mathrm{M}^{2} .
$$

The coefficient $\mathrm{Cp}$ shows how much of the air flow power can profitably be used by the wind wheel, and is also called the coefficient of wind energy use $\xi$. The value of $\xi$ first of all depends on the type of the WT, the shape of its wings and the quality of their production [15].

For high-speed wind turbines with wings of streamlined aerodynamic profile $\xi$ is in the range from 0.42 to 0.46 . This means that the wind wheels of such engines can be profitably used, i. e. transform into mechanical work $42-46 \%$ of the energy that the wind flow passing through the wind wheel has. For slowmoving wind turbines, the values of $\xi$ can be in the range of $0.27-0.33$.

The dimensionless quantities $\xi$ and $\mathrm{Cm}$ are functions of a dimensionless parameter - suction specific speed equal to the ratio:

$$
Z=U / V
$$

where $U$ is the peripheral speed on the outer side of the wind wheel, determined by the formula:

$$
U=\omega \cdot D / 2=\omega \cdot R, \mathrm{~m} / \mathrm{s} .
$$

The speed coefficient is determined by the formula:

$$
Z=\pi \cdot n \cdot D / 60 \cdot V=2 \pi \cdot n \cdot R / V .
$$

The parameters $\mathrm{Cp}, \xi, \mathrm{Cm}$ and $\mathrm{Z}$ are the main operational parameters determining the design perfection and the efficiency of the operation of the wind turbine.

Thus, the completed simulation of wind energy conversion technology into electric technology is the basis of our proposed methodology, which includes the following main stages.

At the first stage grouping of the natural climatic characteristics and area landscape features of the structure arrangement is carried out regarding the type of 
landscape, including surface roughness, calculation of the wind potential of the territory in the speed range from $2-13 \mathrm{~m} / \mathrm{s}$ taking into account annual and month average wind speed and number of prevailing wind direction hours. The aggregate of these parameters determines, in the final analysis, the total wind power (W1) per area unit perpendicular to the direction of the wind flow in the analyzed area.

In the second stage, according to the power demanded by the consumer (W2), various plant variants are selected (by types of wind turbines). Technical characteristics and environmental parameters are determined for each type of WT.

Technical characteristics of the installation are: the diameter of the wind wheel, the height of the mast, the type of the rotation axis, the number of blades and materials they are made of, the lead of a screw. Ecological parameters wind turbines impact, characterizing environmental safety in the area of the facility location: mechanical noise, vibration, infrasound, maintenance intervals, wear resistance of the structure and its elements.

At the third stage the characteristics of the types of wind turbines preliminarily selected in the second stage are compared in order to select the units for the minimum values of wind energy loss $(\Delta \mathrm{Wi})$, capable of providing the power required by the customer:

$$
\Delta W_{i}=W_{1}-W_{2} \cdot \xi,
$$

$\Delta W_{i}$ means losses of wind specific energy, $W$.

At the fourth (final) stage, one of installations having passed the third stage of selection, is selected and that is optimal for ecological and energy efficiency. At this stage, as the resultant criteria for WT we propose ecological and energy efficiency [16-20].

At the same time it is suggested that we choose the optimal choice for the environmental efficiency of wind turbines on the basis of calculating this parameter using the formula:

$$
E_{e f}^{W T}=\left(A_{1}-A_{2}\right) / A_{1} \cdot 100 \%,
$$

where $A_{1}$ is the level of impact of a particular environmental factor on the state of the territory without wind turbine; $A_{2}$ - the level of impact of a separate environmental factor on the state of the territory, taking into account the impact of wind turbines.

In case several variants of the wind turbine will have the same values of environmental efficiency, we suggest the further selection of the optimum wind turbine to be based on the energy efficiency of each option under consideration based on the calculation of the energyconsuming parameter of the wind turbine as a criterion for estimating the energy efficiency:

$$
E_{e}{ }^{W T}=W_{2} / W_{1} \cdot 100, \%,
$$

where $W_{2}$ is used (converted) by WT wind power specific wind energy unit («useful energy»), W; $W_{1}$ is the total available specific wind energy in the territory under consideration («spent energy»), W.

\section{Discussion}

As a result of our studies, we proposed a technique for choosing the technology for converting wind energy into electric power and selecting the design characteristics of wind turbines based on modeling various options for such technologies, as well as selecting optimal parameters of wind turbines based on the principles of ensuring maximum values of ecological and energy efficiency. At the same time, starting from the third stage, in case only one wind turbine remains as a result of the selection the realization of the subsequent stages is not required and the choice of the optimal wind turbine can be completed at the appropriate stage of the procedure.

\section{Conclusions}

Thus, the methodology proposed in the given article makes it possible to select an ecologically and energy efficient wind turbine at the design stage, taking into account the characteristics of the natural-territorial complex and the specific anthropogenic load on the area of the WT location.

\section{References}

1. Solomin E.V., Sirotkin E.A., Seradskaya O.V., International Scientific Journal "Alternative Energy and Ecology", no. 12, 33-34 (2017)

2. Kozhukhov Y.V., Lebedev A.A., Danilishin A.M., Davletgareev E.V., J. CAD/CAM/CAE Observer, no. 7 (107), 81-87 (2016)

3. Popel O.S., Frid S.E., Shpilrain E.E., Scheglov V.N., Izosimov D.B., Tumanov V.L. J. Heat power engineering,no. 3, 42-50 (2006)

4. Popel O.S., Frid S.E., Shpilrain E.E., Izosimov D.B., Tumanov V.L. Prospects of power engineering, no.10, 77-90 (2006)

5. Popel O.S., Evald E., Shpilrain E.E., International Conference "Renewable Energy, 9-13 (2006)

6. Redko I.Y. Multifunctional energy technology complex (METC) is the basis for power supply to remote regions of the Russian Federation: http://pt21.ru/docs/pdf/46.pdf

7. Wind Energy - the facts, (EWEA, London, 2009)

8. Kvitko A.V., Khitskova A.O. Multidisciplinary network electronic scientific journal of Kuban State Agrarian University, no. 97 (2014)

9. Starkov A.S., Grigoriev A.V., Idrisova A.R. Journal of the Magistrate's Bulletin, no.1, 63-64 (2016)

10. Shefter Y.I., Use of wind energy (Energoatomizdat, Moscow, 1983)

11. Twaidel J., Renewable energy sources (Energoatomizdat, Moscow, 1990) 
12. P.P. Bezrukih, Y.D. Arbuzov, G.A. Borisov, Resources and efficiency of renewable energy sources use (Nauka, SPb, 2002)

13. A. Sankovsky.Perspectives for the development of renewable energy in Russia. The results of the project TACIS EuropeAid (ATMOGRAPH, Moscow, 2009)

14. Nikolaev V.G. Ecology and Life, no. 9 (94), (2009)

15. Shishkin N.D. Small energy-economic complexes with renewable energy sources (Gothic, Moscow, 2000)

16. Marchenko O.V., J. Izvestia RAS. Power Engineering, no. 2, 91-103 (2000)

17. Eremin L.M., J. Energetika, no. 3, 22-24 (2003)

18. Grigorash O.V. In Proceedings of KubSAU, no. 6, 192-196 (2011)

19. Grigorash O.V. J. Industrial Power Engineering, no 4, 37-40 (2001)

20. Lyashkov V.I., Kuzmin S.N. Non-traditional and renewable energy sources (Tambov State. Tech. University, Tambov, 2003). 